\title{
Morbidity and Mortality Pattern of Preterm Low Birth Weight Neonates Admitted in Amhara Region Refferal Hospitals of Ethiopia Retrospective Follow- Up Study
}

\author{
Belete Fenta Kebede \\ Jimma Institute of Health Sciences: Jimma University \\ Yalemtsedhay Dagnaw Genie ( $\nabla$ tsehayworld@gmail.com ) \\ Mizan-Tepi University \\ Mulualem Silesh Zerihun \\ Debre Berhan University \\ Desalew Tilahun Beyene \\ Jimma Institute of Health Sciences: Jimma University
}

Research

Keywords: morbidity, mortality, pattern, preterm low birth weight,Amhara region referral hospitals

Posted Date: May 17th, 2021

DOl: https://doi.org/10.21203/rs.3.rs-508365/v1

License: (c) (i) This work is licensed under a Creative Commons Attribution 4.0 International License.

Read Full License 


\section{Abstract \\ Introduction:}

Being born preterm low birth weight was found as the main risk factor for neonatal mortality and development of different morbidities. Even though prevalence of preterm low birth weight neonates is high. There is information gap about prevalence of their morbidity and mortality pattern in this study area.

\section{Objective}

This study was conducted to assess morbidity and mortality pattern of preterm low birth weight neonates admitted in Amhara region referral hospitals of Ethiopia.

\section{Methodology:}

Retrospective follow up study was conducted on preterm low birth weight neonates admitted in Amhara region referral hospital between January 01 /2017 and December 30 /2018. Data were entered to Epidata 4.4.2.1 and exported to STATA 14 for cleaning and analysis. Logistic regression model was used to analyze the data.

\section{Result}

This study revealed that $37.8 \%(95 \% \mathrm{Cl}: 32.4-43.5)$ participants were died. The most common morbidities found in preterm low birth neonates was 219 (75.26\%) hypothermia followed by 201(69.07\%), $145(49.83 \%), 39(13.4 \%)$ and $24(8.25 \%)$ with sepsis, RDS, jaundice, congenital anomaly morbidities respectively. Sepsis (AOR: 2.06(95\% Cl: 1.05-4.02), RDS (AOR: 3.28 (95\% Cl: 1.81-5.95), congenital abnormality (AOR: $3.14(95 \% \mathrm{Cl}$ : $1.16-8.54)$, hypoglycemia (AOR $3.81(95 \% \mathrm{Cl}: 1.27-11.44)$ were independent factors of mortality

\section{Conclusion}

In this study, mortality of preterm low birth neonatal was higher and public health issue. Hypothermia, Sepsis, RDS, jaundice and congenital anomaly were common morbidities. Sepsis, respiratory distress, hypoglycemia and congenital anomaly were factors of mortality.

\section{Introduction}


Globally, in 2017 there were about 5.4 million under five mortality, out of which 2.5 million were died in the first 28 days, with approximately two third and $80 \%$ of the neonates were delivered with preterm and low birth weight respectively(1)... Increasing number in delivery of preterm low birth weight (LBW) neonates were one of the leading causes for the leveling off infant mortality and neonatal mortality rates in 2013 in United States of America (2). In many Asian and African countries being born preterm LBW were found as the main risk factor for development of different morbidities and neonatal mortality $(3,4)$. In Sri Lanka, about $28 \%$ of neonates were died due to Low birth weight and prematurity (4).

Preterm LBW related morbidities were found as main causes of admission in neonatal intensive care unit (NICU). In Bangladesh 12.4\% of admission were due to preterm LBW and preterm LBW were the cause for $6.5 \%$ of deaths (5). Furthermore preterm LBW lead to prolonged stay of neonates in the hospital and can lead to adverse neurodevelopmental outcome shows greatest concern for the family and the society in future (6). . In different regions of Ethiopia being born preterm low birth weight was the major contributor for neonatal deaths and neonate born with less birth weight and preterm showed higher mortality during the neonatal period than normal birth weight and term neonates $(7,8)(9)(10)$. In southwest region of Ethiopia from all neonatal deaths of $22.8 \%$, more than two third $(76 \%)$ of death were caused by LBW and prematurity (10).

Despite the initiation of modern techniques of NICU facilities, preterm LBW neonates are still at high risk for the development of numerous morbidities (11).The overall mortality of preterm low birth weight neonates varies depending on the pattern of morbidities (12). Preterm low birth weight neonates are predisposed to infectious diseases due to their immature immune system and develops many sever morbidities such as; hypoglycemia, respiratory distress syndrome (RDS) (13), sepsis ,jaundice, apnea and birth asphyxia $(14,15)$. The rate of mortality rate in preterm LBW neonates was different depending on morbidity type $(16,17)$. The risk of developing morbidities was varying in different category of preterm LBW neonates. The extremely low birth weight (ELBW) and extremely preterm neonates had higher rates of all the morbidities and mortalities(18).

Some trials are started to implement now for prevention of preterm LBW birth and reductions of neonatal morbidity and mortality related with preterm LBW. The sustainable development goal three emphasizes on reducing neonatal deaths with goal of 12 neonatal deaths per 1000 live births per country by 2030 through different interventions including of: kangaroo mother care and extra support for feeding Low birth weight and preterm babies with breast milk and other many interventions at postnatal period (19).

Despite these trials many finding of previous studies in Ethiopia had identified high prevalence of preterm LBW neonates and had higher risk of neonatal morbidity and mortality in those preterm LBW neonates. Eventhouh preterm LBW birth is high to our knowledge there is information gap about prevalence of morbidity and their mortality in preterm low birth weight neonates in this study area; therefore, this study is planning to fill this information gap.

\section{Method And Materials}




\section{Study area, design and period}

The study was conducted in selected referral hospitals of Amhara region. Among from all four referral hospitals in the region; Felege Hiwot Referral Hospital (FHRH), Debremarkos, Dessie and Debrebirhan, two of them were selected by lottery method (FHRH, Dessie referral hospital). Institutional based retrospective follow up study was conducted among preterm LBW neonates admitted in NICU ward of selected Amhara region referral hospitals between January 01/2017 and December $30 / 2018$. The study was conducted from December 2018 to June 2019.

\section{Population, eligibility criteria}

All neonates with gestational age of less than 37 weeks weighing500-2499g admitted in Amhara region referral hospitals of NICU ward were source population. All selected preterm low birth weight neonates admitted in Amhara region referral hospitals of NICU ward from January 01/2017 to December 30 /2018 were study population. Live birth neonates with gestational age of less than 37 weeks weighing 500$2499 \mathrm{~g}$ admitted in Amhara region referral hospitals of NICU ward were eligible in the study.

\section{Sampling techniques and procedure}

From four referral hospitals found in the Amhara region, FHRH and Dessie Referral Hospital were selected by lottery method. All preterm LBW neonates admitted in NICU ward between January/ 1 /2017December/ 30 /2018 were recruited by using admission registration book by recording their medical record number sequentially. The samples were proportionally allocated for each hospital. Simple random sampling technique was used to select required number of study participant's.

\section{Variables of the study}

The dependent variable was outcome of preterm LBW neonates dichotomized into death or alive. The independent variables of the study were include: Socio-demographic variables (Sex of neonate, age of neonate, age of mother), Maternal and obstetric related variables (Maternal disease (HIV, DM), pregnancy status, Pregnancy induced hypertension), complication/morbidity related variables (Sepsis, necrotizing enterocolitis, intraventricular hemorrhage, asphyxia, RDS, jaundice, pulmonary hemorrhage, congenital anomalies, hypothermia, hypoglycemia) and neonatal related variables (place of delivery, mode of delivery) were included.

\section{Data collection tools and procedures}

After reviewing of different literatures, the checklist was adapted to address the objective of the study. The checklist consists of the information on maternal and neonatal socio-demographic data, neonatal related factors, complication/morbidity factors, maternal and obstetrics related factors. Data were extracted from each individual neonatal medical chart by using a structured checklist adapted from different literature.

\section{Data quality assurance}


To insure quality of data, different measures were undertaken. One day training was given to data collectors and supervisors on the objective of the study and how to gather information by using the prepared data extraction checklist. Data were collected by six nurses working in NICU who were taking $\mathrm{NICU}$ training. One MSC nurse supervisor was assigned for support and facilitation of data collection in each selected site of data collection area. Supervision of data collectors about data collection process was done by supervisor. Supervisor checked daily evaluation about completeness of the filled checklist.

\section{Data processing, analysis and presentation}

After checking data completeness and consistency, the collected data were coded and entered toEpi-data statistical software package version 4.4.2.1. Then the data exported to STATA version 14 for cleaning and analysis. Descriptive statistics was carried out and presented using tables, and texts. Bivariate and multivariable analysis was done in logistic regression to determine the association between factor variables and the dependent variable. Based on bivariate analysis, those variables having p-value $<0.25$ in the binary logistic regression were transferred to the multivariable analysis and those variables having P-value $<0.05$ at $95 \%$ confidence level were considered as independent factors for mortality of preterm low birth weight neonates. The final measure of association between independent and dependent variables was expressed by adjusted odds ratio.

\section{Results}

Two hundred ninety one preterm low birth neonates' charts were reviewed and each individual preterm low birth weight neonates had different length of hospital stay.

\section{Neonatal and maternal socio-demographic characteristics.}

From 291 total sampled preterm low birthweight neonates, majority 185 (63.57\%) were male. Two hundred five $(70.45 \%)$ mothers were belonging to the age category of 20-34 years old.

\section{Maternal and obstetrics related characteristics}

Majority $45(15.46 \%)$ of preterm low birth weight neonates were born from mothers who had a diagnosis of pregnancy induced hypertension.

\section{Neonatal related characteristics}

Two hundred seventy three (93.81\%) preterm low birth weight neonates were born in health institutions. Majority $(79.73 \%)$ of the preterm low birth weight neonates were born via vaginal mode of delivery. Two hundred nineteen $(80.22 \%)$ preterm low birth weight neonates had less than seven APGAR score at first minute. One hundred fifty two $(55.68 \%)$ preterm low birth weight neonates had more than seven APGAR score at five minute. 


\section{Morbidity And Mortality Pattern}

\section{Preterm Low birth weight related morbidities characters}

In this study 219 (75.26\%), 201(69.07\%), 145(49.83\%), 39(13.4\%), 24(8.25\%), and 21(7.22\%) 10(3.44\%), $23(7.9 \%)$ and $7(2.41 \%)$ of neonates were diagnosed with hypothermia, sepsis, RDS, jaundice, congenital anomaly ,hypoglycemia, necrotizing enterocolitis ,meningitis, and perinatal asphyxia morbidities respectively.

\section{Factors of preterm low birth weight neonatal mortality}

In this study, the overall proportion of preterm low birth weight neonatal mortality was $37.8 \%$ ( $95 \% \mathrm{Cl}$ : 32.4-43.5). In this study Sepsis, RDS, congenital anomaly and hypoglycemia were remained independent factors of mortality for preterm low birth weight neonates (Table.5).

In this study preterm low birth weight neonates with sepsis had $6 \%$ higher odds of mortality as compared to neonates without sepsis (AOR: $2.06(95 \% \mathrm{Cl}: 1.05-4.02)$. Preterm low birth weight neonates diagnosed with RDS had 3.28 times higher odds of mortality than preterm low birth weight neonates without RDS (AOR: 3.28 (95\% Cl: 1.81-5.95). Preterm low birth weight neonates with congenital anomaly had 3.14 times odds of mortality as compared to preterm low birth weight neonates without congenital abnormality (AOR: 3.14(95\% Cl:1.16-8.54).Preterm low birth weight neonates with a diagnosis of hypoglycemia had $81 \%$ higher of odds of mortality than their counterparts (AOR 3.81(95\% Cl: $1.27-$ 11.44).

\section{Discussion}

This retrospective follow up study was carried out to determine pattern of preterm LBW neonates' morbidity, mortality and factors associated with their mortality. In this study, the overall proportion of preterm low birth weight neonatal mortality was $37.8 \%(95 \% \mathrm{Cl}$ : $32.4-43.5)$. This result is higher than studies conducted in India 6.5\%(18)and Iran 28.7\%(20). The difference from study in Iran might be that study was excluded neonates with severe fetal malformations whereas this study did not exclude those neonates, which may increase mortality risk. The discrepancy from study in India may be due to that the study focusing only on short-term outcomes, whereas our study was on neonatal period.

However, this result is lower than study conductedinlsfahan city, Iran $64.4 \%(21)$ andTelangana, India88.8\%(22). The possible reason for this difference might be difference in inclusion criteria, where study in Iran involves neonates with birth weight category of less than one thousand five hundred grams and gestationalage of less than thirty weeks. The risk of mortality may become high as birth weight of and gestational age of neonate is decreased.

Our study was also revealed that neonatal hypothermia (75.26\%), Sepsis (69.07\%), RDS, (49.83\%), jaundice, $(13.4 \%)$ and congenital anomaly $(8.25 \%)$ were the most common morbidities and reason for 
admission to NICU. This result is supported by studies conducted in Shardahospital, India (16), Western Nepal(17), Telangana, India(18), Isfahan city, Iran(21), teachinghospital, Telangana, India (22), New South Wales and Australian Capital Territory(23).

In this study preterm low birth weight neonates with sepsis had $6 \%$ higher odds of mortality as compared to neonates without sepsis (AOR: $2.06(95 \% \mathrm{Cl}: 1.05-4.02)$. This result was supported by the study conducted in Telangana, India (18)New South Wales and Australian Capital Territory (23),Mahatma Gandhi Memorial Government Hospital, India (24). The possible reason might be that preterm low birth weight neonates mostly had immature host defense mechanisms makes them susceptible to devastating infection that finally may leads to neonatal death.

In addition Preterm low birth weight neonates diagnosed with RDS had 3.28 times higher odds of mortality than preterm low birth weight neonates without RDS (AOR: 3.28 (95\% Cl: 1.81-5.95). This result was supported by study conducted inAga Khan University Hospital, Karachi, Pakistan(6), Telangana, India(18), New South Wales and Australian Capital Territory (23),Mahatma Gandhi Memorial Government Hospital, India(24).The possible reason might be that neonates with RDS had complication of lung collapse that may facilitate death easily in preterm low birth weight neonates.

Preterm low birth weight neonates with a diagnosis of hypoglycemia had $81 \%$ higher of odds of mortality than their counterparts (AOR 3.81(95\%Cl: 1.27-11.44). This was supported by study done in Telangana, India (18), Mahatma Gandhi Memorial Government Hospital (24). This might be due to the fact that preterm neonates had immature organ that leads to failure in glycogen storage may end up with death. In addition this study found that preterm low birth weight neonates with a diagnosis of congenital anomaly had 3.14 times higher odds of death as compared to their counter parts (AOR: 3.14(95\%Cl:1.16-8.54). This result is supported by other studies conducted in Telangana, Indi(6),Mahatma Gandhi Memorial Government Hospital, India(24).The possible reason might be preterm low birth neonates with congenital anomalies have risk of developing different systemic complication like neurological, cardiovascular, respiratory and gastrointestinal those can may leads to mortality.

\section{Conclusion}

In conclusion, this study revealed that morbidity and mortality of preterm low birth neonatal death was higher in this setting than national estimates of SDGS and findings of Ethiopian demographic health survey2019. Hypothermia, Sepsis, RDS, jaundice and congenital anomaly were the most common morbidities. Neonatal sepsis, respiratory distress, hypoglycemia and congenital anomaly were independent factors of mortality among preterm low birth weight neonates.

\section{Abbreviations}

DM 
Diabetes Mellitus, FHRH:Felege Hiwot Referral Hospital, GA:Gestational Age, HIV:Human Immune Virus, LBW:Low Birth Weight, NEC:Necrotizing Enterocolitis, NICU:Neonatal Intensive Care Unit, PIH:Pregnancy Induced Hypertension, PTLBW:Preterm Low Birth Weight, RDS:Respiratory Distress

\section{Declarations}

\section{Acknowledgement}

It is our pleasure to thank Felege hiwot referral hospital and Dessie referral hospital staffs of pediatric, neonatology case team, and the card extractors. It is also our pleasure to thank the data collectors and supervisors.

\section{Funding}

There is no funding to report.

\section{Availability of data and materials}

The raw data file could be provided for research purpose only, upon request via e-mail of the corresponding author.

\section{Authors' contributions}

All authors contributed equally to this work.YD, BF, MS \$ DT participated in all phases of the study including topic selection, design, data collection, data analysis and interpretation. All authors also contribute to write this manuscript. All authors read and approved the final manuscript.

\section{Competing interests}

The authors declare that they have no competing interests.

\section{Consent for publication}

No applicable

\section{Ethics approval and consent to participate}

To conduct this study ethical clearance letter was obtained from institutional review board of Mekelle University, college of health sciences. Permission letters were written for FHRH and Dessie referral hospital. Data were collected after consent of cooperation was obtained from Felege Hiwot referral hospital and Dessie referral hospital administrator.

\section{References}


1. WHO. Survive \& thrive. Delic Living [Internet]. 2019;29(8):20-37. Available from: https://apps.who.int/iris/bitstream/handle/10665/326495/9789241515887-eng.pdf

2. Lau C, Ambalavanan N, Chakraborty H, Wingate MS, Carlo WA. Extremely low birth weight and infant mortality rates in the United States. Pediatrics. 2013;131(5):855-60.

3. Article 0. Neonatal Morbidity and Mortality Pattern in a Tertiary Care Neonatal Unit of a Teaching Hospital. 2014;4:7-12.

4. Aah P, Thuvarakan P, Mvc DS. Classification of perinatal deaths according to ICD-PM: An audit on perinatal post-mortems in a tertiary care centre in Sri Lanka. 2017;(June):31-5.

5. Hamid F, Quaium SMM, Rahman A, Ahmad AR, Khan S, Hussain T, et al. Audit of Neonatal Morbidity and Mortality in A Tertiary Care Hospital, Sylhet. Chattagram Maa-O-Shishu Hosp Med Coll J. 2017;15(2):45-8.

6. Khan MR, Maheshwari PK, Shamim H, Ahmed S, Ali SR. Morbidity pattern of sick hospitalized preterm infants in Karachi, Pakistan. J Pak Med Assoc. 2012;62(4):386-8.

7. Mengesha HG, Wuneh AD, Lerebo WT, Tekle TH. Survival of neonates and predictors of their mortality in Tigray region, Northern Ethiopia: prospective cohort study. BMC Pregnancy Childbirth [Internet]. 2016;(December). Available from: http://dx.doi.org/10.1186/s12884-016-0994-9

8. Kebede B, Gebeyehu A, Sharma HR, Yifru S. Prevalence and associated factors of neonatal mortality in North Gondar Zone, Northwest Ethiopia. Ethiop J Heal Dev. 2012;26(2):66-71.

9. Kassie A, Mekasha A, Tadesse BT, Worku A. P re d i c t o r s o f e a rl y n e o n a t a I m o r t a l i t y a t aneonatalintensivecareunitofaspecializedreferralteachinghospita I i n E t h i o p i a. 2012;(January).

10. Mekonnen T, Tenu T, Aklilu T AT (2018). Assessment of Neonatal Death and Causes among Admitted Neonates in Neonatal Intensive Care Unit of Mizan Tepi University Teaching Hospital, Bench Maji Zone, South-West Ethiopia, 2018. Clinics Mother Child Healt. 2018;15(4).

11. Chidiebere ODI, Uchenna E, Christian I, Nwabueze Al, Stephen AO, Ifeyinwa O. The Low-birth weight Infants: Pattern of Morbidity and Mortality in a Tertiary Healthcare Facility in the South Eastern Nigeria. Ann Med Health Sci Res [Internet]. 2018;8(April):4-10. Available from: https://www.amhsr.org/

12. Janaswamy VS, Kodandapani Y, Lathasree P. Mortality and Morbidity Profile of Low Birth Weight Babies ata Tertiary Care Hospital. IOSR J Dent Med Sci Ver I [Internet]. 2016;15(3):2279-861. Available from: www.iosrjournals.org

13. Mukherjee S, Shaw SC, Devgan A, Srivastava AK, Mallige A. Survival and morbidities in very low birth weight (VLBW) infants in a tertiary care teaching hospital. Int J Contemp Pediatr. 2017;4(6):2170.

14. Arakhita Swain NN. Http://Www.Omicsgroup.Org/Journals/Pulmonary-Agenesis-With-Dextrocardiaand-Hypertrophic-Cardiomyopathy-First-Case-Report-2167-0897.1000141.Php?Aid=26283. J Neonatal Biol. 2014;03(03).

15. Baki MA, Haque A, Mohsin F, Nahar J, Akhter S, Begum T, et al. Risk Factors for Mortality in Neonates with Birth Weight <1500 gm. BIRDEM Med J. 2012;2(1):19-22. 
16. Hassan N, Mukhopadhyay S, Mohan S. Morbidity and mortality profile of preterm neonates admitted in neonatal intensive care unit of a tertiary care centre in Western Uttar Pradesh, India. Int J Contemp Pediatr. 2019;6(5):1859.

17. Paudel L, Kalakheti B, Sharma K. Prevalence and Outcome of Preterm Neonates Admitted to Neonatal Unit of a Tertiary Care Center in Western Nepal. Journal of Lumbini Medical College. 2018;6(2):6 pages. DOI: 10.22502/jlmc.v6i2.218. Epub: 2018 Dec 8.

18. Hasthi UR, Ashwani N, Kumar CS, Chejeti SR. Morbidity and Mortality Patterns in Small for Gestational Age versus Appropriate for Gestational Age Preterm Neonates Admitted in Level II Neonatal Intensive Care Unit: A Observational Study. 2017;4(10):133-6.

19. (EWE Child. The global strategy for women's children's and adolescents' health (2016-2030):. I at glance . 2015. ). STRATEGY. 2016;

20. Ghorbani F, Heidarzadeh M, Dastgiri S, Ghazi M, Farshi MR. Survival of Premature and Low Birth Weight Infants: A Multicenter, Prospective, Cohort Study in Iran. 2017;8(1).

21. Navaei F, Aliabady B, Moghtaderi J, Moghtaderi M, Kelishadi R. Early outcome of preterm infants with birth weight of $1500 \mathrm{~g}$ or less and gestational age of 30 weeks or less in Isfahan city, Iran. 2010;6(3).

22. Pabbati J, Subramanian P, Renikuntla M. Morbidity and mortality of low birth weight babies in early neonatal period in a rural area teaching hospital, Telangana, India. Int J Contemp Pediatr. 2019;6(4):1582.

23. Schindler T, Koller-smith L, Lui K, Bajuk B, Bolisetty S. Causes of death in very preterm infants cared for in neonatal intensive care units: a population-based retrospective cohort study. 2017;1-9.

24. Saminathan D, Mythili B, Ramesh E, Zacharias AM. Incidence, Mortality Pattern, and Outcome of Low Birth Weight Babies Admitted in a Rural Tertiary Care Center: A Retrospective Study. 2016;4(1):51-4.

\section{Tables}

Table 1

Socio-demographic characteristics of preterm low birth weight neonates and their mothers admitted in NICU of Amhara region referral hospitals, Ethiopia, $2019(n=291)$.

\begin{tabular}{|lllll|}
\hline Characteristics & Category & $\begin{array}{l}\text { Total } \mathbf{N}(\%) \\
\mathbf{N}=\mathbf{2 9 1}\end{array}$ & $\begin{array}{l}\text { Alive N (\%) } \\
\mathbf{N}=181\end{array}$ & $\begin{array}{l}\text { Death N (\%) } \\
\mathbf{N}=110\end{array}$ \\
\hline Sex of the neonate & Female & $106(36.43)$ & $70(66.04)$ & $36(33.96)$ \\
\cline { 2 - 5 } & Male & $185(63.57)$ & $111(60)$ & $74(40)$ \\
\hline Maternal age (year) & $<20$ & $46(15.81)$ & $29(63.04)$ & $17(36.96)$ \\
\cline { 2 - 5 } & $20-34$ & $205(70.45)$ & $128(62.44)$ & $77(37.56)$ \\
\hline & $>=35$ & $40(13.75)$ & $24(62.2)$ & $16(37.8)$ \\
\hline
\end{tabular}


Table 2: Maternal medical and obstetrics characteristics of preterm low birth weight neonates and neonatal outcome admitted in NICU of Amhara region referral hospitals, Ethiopia, $2019(n=291)$

\begin{tabular}{|c|c|c|c|c|c|}
\hline \multirow[t]{2}{*}{ Characteristics } & & \multirow[t]{2}{*}{ Category } & \multirow{2}{*}{$\begin{array}{l}\text { Total N (\%) } \\
N=291\end{array}$} & \multirow{2}{*}{$\begin{array}{l}\text { AliveN(\%) } \\
N=181\end{array}$} & \multirow{2}{*}{$\begin{array}{l}\text { Death } \\
N(\%) \\
N=110\end{array}$} \\
\hline & & & & & \\
\hline \multirow{2}{*}{\multicolumn{2}{|c|}{$\begin{array}{l}\text { Maternal chronic Medical } \\
\text { disease }\end{array}$}} & No & 281(96.56) & $\begin{array}{l}178 \\
(63.35)\end{array}$ & )$^{103(36.65}$ \\
\hline & & Yes & $10(3.44)$ & $3(30)$ & $7(70)$ \\
\hline \multirow{6}{*}{$\begin{array}{l}\text { Maternal chronic } \\
\text { Medical } \\
\text { disease }\end{array}$} & \multirow[t]{2}{*}{ HIV } & No & 285(97.94) & $\begin{array}{l}179 \\
(62.81)\end{array}$ & 106(37.19) \\
\hline & & Yes & $6(2.06)$ & 2(33.33) & $4(66.67)$ \\
\hline & \multirow[t]{2}{*}{ DM } & No & 289(99.31) & )$^{181(62.63}$ & $\begin{array}{l}108 \\
(37.37)\end{array}$ \\
\hline & & Yes & $2(0.69)$ & - & $2(100)$ \\
\hline & \multirow[t]{2}{*}{ Others } & No & 289(99.31) & )$^{180(62.28}$ & $\begin{array}{l}109( \\
37.72)\end{array}$ \\
\hline & & Yes & $2(0.69)$ & $1(50)$ & $1(50)$ \\
\hline \multirow{2}{*}{\multicolumn{2}{|c|}{ Obstetric complications }} & No & 228(78.35) & )$^{149(65.35}$ & 79 (34.65) \\
\hline & & Yes & $63(21.65)$ & $32(50.79)$ & $31(49.21)$ \\
\hline \multirow[t]{6}{*}{ Obstetric complication } & \multirow[t]{2}{*}{$\mathrm{PIH}$} & No & 246(84.54) & $158(64.23)$ & $88(35.77)$ \\
\hline & & Yes & $45(15.46)$ & $23(51.11)$ & 22(48.89) \\
\hline & \multirow[t]{2}{*}{$\begin{array}{l}\text { placenta- } \\
\text { abruption }\end{array}$} & No & 279(95.88) & )$^{175(62.72}$ & $\begin{array}{l}104( \\
37.28)\end{array}$ \\
\hline & & Yes & $12(4.12)$ & $6(50)$ & $6(50)$ \\
\hline & \multirow[t]{2}{*}{ placenta-Previa } & No & 285(97.94) & )$^{178(62.46}$ & 107(37.54) \\
\hline & & Yes & $12(2.06)$ & $6(50)$ & $6(50)$ \\
\hline
\end{tabular}

Table.3: medical and surgical morbidity related factors of preterm low birthweight neonates admitted in NICU of Amhara region referral hospitals, Ethiopia, $2019(n=291)$. 


\begin{tabular}{|c|c|c|c|c|}
\hline \multirow[t]{2}{*}{ Morbidity characteristics } & \multirow[t]{2}{*}{ Category } & \multirow{2}{*}{$\begin{array}{l}\text { Total N(\%) } \\
\mathrm{N}=291\end{array}$} & \multirow{2}{*}{$\begin{array}{l}\text { Alive } N(\%) \\
N=181\end{array}$} & \multirow{2}{*}{$\begin{array}{l}\text { Death } N(\%) \\
N=110\end{array}$} \\
\hline & & & & \\
\hline \multirow[t]{2}{*}{ Sepsis } & No & $90(30.93)$ & $69(76.67)$ & $21(23.33)$ \\
\hline & Yes & $201(69.07)$ & $112(55.72)$ & $89(44.28)$ \\
\hline \multirow[t]{2}{*}{ RDS } & No & $146(50.17)$ & 115(78.77) & $31(21.23)$ \\
\hline & Yes & $145(49.83)$ & $66(45.52)$ & $79(54.48)$ \\
\hline \multirow[t]{2}{*}{ Jaundice } & No & $251(86.6)$ & 159(63.10) & $93(36.90)$ \\
\hline & Yes & $39(13.4)$ & $22(56.41)$ & 17(43.59) \\
\hline \multirow[t]{2}{*}{ Congenital anomaly } & No & 267(91.75) & $170(63.67)$ & $97(36.33)$ \\
\hline & Yes & $24(8.25)$ & $11(45.83)$ & $13(54.17)$ \\
\hline \multirow[t]{2}{*}{ Hypoglycemia } & No & 270(92.78) & 172(63.7) & $98(36.30)$ \\
\hline & Yes & $21(7.22)$ & $9(42.86)$ & $12(57.14)$ \\
\hline \multirow[t]{2}{*}{ Hypothermia } & No & $72(24.74)$ & $50(69.44)$ & $22(30.56)$ \\
\hline & Yes & $219(75.26)$ & 131(59.82) & $88(40.18)$ \\
\hline \multirow[t]{2}{*}{ Perinatal asphyxia } & No & 284(97.59) & 181(63.73) & $103(36.27)$ \\
\hline & Yes & $7(2.41)$ & - & $7(100)$ \\
\hline \multirow[t]{2}{*}{ Meningitis } & No & 268(92.1) & $167(62.31)$ & 101(37.69) \\
\hline & Yes & $23(7.90)$ & $14(60.87)$ & $9(39.13)$ \\
\hline \multirow[t]{2}{*}{ Necrotizing enter colitis } & No & 281(96.56) & $179(63.7)$ & 102(36.3) \\
\hline & Yes & $10(3.44)$ & $2(20)$ & $8(80)$ \\
\hline
\end{tabular}

Table.4: Neonatal related characteristics of preterm low birthweight neonates and neonatal outcome admitted in NICU of Amhara region referral hospitals, Ethiopia, $2019(n=291)$. 


\begin{tabular}{|lllll|}
\hline characteristics & Category & Total N (\%) & Alive N (\%) & Death N (\%) \\
& & $\mathbf{N = 2 9 1}$ & $\mathbf{N = 2 8 1}$ & $\mathbf{N = 1 1 0}$ \\
\hline Place of delivery & Health institution & $273(93.81)$ & $171(62.64)$ & $102(37.36)$ \\
\cline { 2 - 5 } & Home & $18(6.19)$ & $10(55.56)$ & $8(44.44)$ \\
\hline Mode of delivery & Cesarean & $59(20.27)$ & $43(72.88)$ & $16(27.12)$ \\
\cline { 2 - 5 } & Vaginal & $232(79.73)$ & $138(59.48)$ & $94(40.52)$ \\
\hline Type of pregnancy & Single & $185(63.57)$ & $118(63.78)$ & $67(36.22)$ \\
\cline { 2 - 5 } & Multiple & $106(36.43)$ & $63(59.43)$ & $43(40.57)$ \\
\hline APGAR score & $<7$ & $219(80.22)$ & $129(58.9)$ & $190(41.1)$ \\
\cline { 2 - 5 } 1st min. & $>=7$ & $54(19.78)$ & $42(77.78)$ & $12(22.22)$ \\
\hline APGAR score & $<7$ & $121(44.32)$ & $65(53.72)$ & $56(46.28)$ \\
\hline 5th min. & $>=7$ & $152(55.68)$ & $106(69.74)$ & $46(30.26)$ \\
\cline { 2 - 5 }
\end{tabular}

Table.5: factors associated with preterm low birthweight neonatal mortality of admitted in NICU of Amhara region referral hospitals, Ethiopia, $2019(n=291)$. 


\begin{tabular}{|c|c|c|c|c|c|c|}
\hline Characteristics & Category & Alive & Death & $\operatorname{COR}(95 \% \mathrm{Cl})$ & AOR(95\% Cl) & $P>|z|$ \\
\hline \multirow[t]{2}{*}{ Sepsis } & No & 69 & 21 & 1 & 1 & \\
\hline & Yes & 112 & 89 & $\begin{array}{l}2.61(1.49- \\
4.58)\end{array}$ & $2.06(1.05-4.02)$ & $0.035^{\star \star}$ \\
\hline \multirow[t]{2}{*}{ RDS } & No & 115 & 31 & 1 & 1 & \\
\hline & Yes & 66 & 79 & $\begin{array}{l}4.44(2.66- \\
7.42)\end{array}$ & $3.28(1.81-5.95)$ & $0.000 * \star$ \\
\hline \multirow{2}{*}{$\begin{array}{l}\text { Congenital } \\
\text { anomaly }\end{array}$} & No & 170 & 97 & 1 & 1 & \\
\hline & Yes & 11 & 13 & $2.07(.89-4.81)$ & $3.14(1.16-8.54)$ & $0.025^{\star \star}$ \\
\hline \multirow[t]{2}{*}{ Hypoglycemia } & No & 172 & 98 & 1 & 1 & \\
\hline & Yes & 9 & 12 & $2.34(.95-5.75)$ & $3.81(1.27-11.44)$ & $0.017 * \star$ \\
\hline \multirow[t]{2}{*}{ Hypothermia } & No & 50 & 22 & 1 & 1 & \\
\hline & Yes & 131 & 88 & $1.53(.86-2.7)$ & $1.34(.68-2.65)$ & 0.401 \\
\hline \multirow[t]{2}{*}{$\mathrm{PIH}$} & No & 158 & 88 & 1 & 1 & \\
\hline & Yes & 23 & 22 & $1.72(.91-3.26)$ & $1.98(.92-4.25)$ & 0.081 \\
\hline \multirow[t]{2}{*}{ APGAR 1st min. } & $<7$ & 129 & 190 & $2.44(1.22-4.9)$ & $1.72(.72-4.13)$ & 0.228 \\
\hline & $>=7$ & 42 & 12 & 1 & 1 & \\
\hline \multirow[t]{2}{*}{ APGAR 5th min } & $<7$ & 65 & 56 & $\begin{array}{l}1.99(1.21- \\
3.26)\end{array}$ & $1.24(.66-2.31)$ & 0.513 \\
\hline & $>=7$ & 106 & 46 & 1 & 1 & \\
\hline
\end{tabular}

